\title{
In vitro efficacy of triclosan coated polyglactin 910 suture against common bacterial pathogen causing surgical site infection
}

\author{
Manideepa SenGupta ${ }^{1}$, Dibyendu Banerjee', Mallika Sengupta ${ }^{2}$, Soma Sarkar ${ }^{1}$, \\ Soumyabrata Nag', RK Manojkumar Singh ${ }^{3}$ \\ 1. Department Of Microbiology, Medical College, Kolkata, West-Bengal, India \\ 2. Department Of Microbiology, CMC Vellore, India
}

3. Department of Microbiology, Jawaharlal Nehru Institute of Medical Sciences, Imphal, Manipur, India

\begin{abstract}
Surgical-site infections (SSIs) increase morbidity and mortality in post-surgical patients as well as represent an economic burden to healthcare systems. The aim of this study was to evaluate the in-vitro efficacy of triclosan coated polyglactin 910 suture against the common bacteria isolated from post-operative wound infection. Our goal was to establish whether the use of a triclosan coated suture would reduce the incidence of microbial colonisation of suture material thus reducing the rate of surgical site infection. Similar length $(4 \mathrm{~cm})$ of triclosan coated and uncoated sutures were put on the lawn culture made on Mueller Hinton agar by 0.5 McFarland standard suspensions prepared by touching 4-5 colonies of each bacterium isolated from post-operative wound infections. After overnight incubation at $37^{\circ} \mathrm{C}$, the zone of inhibition around triclosan coated sutures was compared to the zone of inhibition that was found around uncoated sutures. Among $271(81.87 \%)$ positive cultures from 331 post-operative wound samples, the commonest bacterial isolates were Staphylococcus aureus (29.52\%), followed by Escherichia coli (17.34\%), Klebsiella spp. (15.13\%), Coagulase negative Staphylococcus (9.96\%), Pseudomonas spp. (9.22\%), Proteus spp. (6.64\%), Enterococcus spp. (5.53\%), Citrobacter spp. (3.69\%), and Acinetobacter spp. (2.95\%). It was found that after overnight incubation at $37^{\circ} \mathrm{C}$, a good zone of inhibition was present around triclosan coated sutures in all isolates except Pseudomonas spp. and Enterococcus spp. - but minimal or no such zone was seen around uncoated sutures. Triclosan coated suture showed good antibacterial activity in-vitro and may be assumed to significantly reduce the SSI rate, cost and duration of hospital stay as it is highly effective in-vitro against the common bacteria isolated from post-operative wound infection.
\end{abstract}

Keywords: Surgical wound infection and prevention and control; Sutures; Triclosan

\section{Corresponding author}

Dr Soma Sarkar

Department Of Microbiology, Medical College, Kolkata, 88, College Street, Kolkata 700073 West-Bengal, India Email: drdipsoma@gmail.com 


\section{Introduction}

SSI is a common problem comprising a major part of health care associated infection (HAl) worldwide. Prevention and treatment of SSI is challenging as it prolongs hospital stay, has an effect on quality of life and is a financial burden. The causes of wound infections are multifactorial. Co-morbidity, malnutrition, and nicotine are important risk factors. Implanted foreign materials, including sutures, increase the risk of SSI. ${ }^{2,3}$ Sutures in contaminated tissues may enable micro-organisms to penetrate deeper ${ }^{4}$ and the size of inoculum micro-organisms needed to cause an SSI is $10^{5}$-times lower when foreign material is present. ${ }^{5}$ Biofilms around a suture may protect microorganisms from host defence mechanisms. ${ }^{6,7}$ There have been trials to study the role of antibiotic as well as antiseptic coated sutures to prevent SSI. ${ }^{8-10}$ Triclosan (2,4,4'-trichloro-2'-hydroxydiphenyl ether) is a broadspectrum biocide that has been used for more than 30 years in various products such as toothpaste and soaps. In the beginning the mode of action was supposed to be through nonspecific disruption of the bacterial cell membrane. ${ }^{11}$ Newer studies, however, reveal that the target of triclosan is the Fab I gene, which blocks bacterial fatty acid synthesis (particularly the enzyme enoyl-acyl carrier protein reductase [ENR]). ${ }^{12,13,14}$ As triclosan is an antiseptic and not an antibiotic, the risk of resistance is very low. ${ }^{15}$ The safety of triclosan has already been investigated in several experimental studies. $^{2,16,17,18}$

In this study the in-vitro efficacy of triclosan coated polyglactin 910 suture against the common bacteria isolated from post-operative wound infection was evaluated and compared with non-triclosan coated sutures.

\section{Materials and Methods}

The study was carried out from February 2012 to May 2012 in the department of Microbiology, Medical College, Kolkata after the approval of ethics committee.

\section{Isolation and identification of bacteria from post- operative wound infections}

The samples collected from post-operative wound infections were inoculated in nutrient agar, blood agar and Mac Conkey's agar media for isolation of the causative bacteria and identification was done by conventional biochemical tests.

\section{In-vitro testing of triclosan coated and uncoated suture against the bacteria isolated from SSI}

0.5 McFarland standard suspensions were prepared from touching 4-5 colonies of each isolated bacterium and lawn cultures were made on Mueller Hinton agar. A small length $(4 \mathrm{~cm})$ of triclosan coated suture and a similar length of uncoated suture were placed on two halves of each plate and incubated at $37^{\circ} \mathrm{C}$. After overnight incubation, the zone of inhibition around triclosan coated suture was compared to the zone of inhibition that was found around uncoated suture.

\section{Testing of triclosan coated suture against MRSA and MRSE}

After overnight incubation at $37^{\circ} \mathrm{C}$, only those $S$. aureus strains showing a zone of inhibition less than $21 \mathrm{~mm}$ diameter around cefoxitin discs $(30 \mu \mathrm{g})$ were taken as MRSA strains. Similarly, the $S$. epidermidis strains showing a zone of inhibition of less than 24 $\mathrm{mm}$ diameter around cefoxitin discs were considered as MRSE. Again, 0.5 McFarland standard suspensions were made from each of these strains and lawn cultures were made on MHA plates. This time, along with coated and uncoated sutures on either half of each plate, a cefoxitin disc was also paced in the centre to observe the activity of coated suture against MRSA and MRSE in comparison to uncoated suture.

\section{Testing of triclosan coated suture against skin commensals}

To detect the effect of triclosan coated suture against skin commensals, 20 skin swabs were collected from healthy individuals and inoculated into $\mathrm{BHI}$ broth. After overnight incubation at $37^{\circ} \mathrm{C}$, the turbidity of the broth was matched with $0.5 \mathrm{McF}$ arland standard and lawn cultures were made on MHA plates. Same procedure was repeated with coated and uncoated sutures.

\section{Results}

\section{Isolation and identification of bacteria from post- operative wound infections}

Among 331 samples collected from patients with SSI in three and half month's duration, positive culture was obtained from 271 (81.87\%) cases. The commonest bacterial isolates were $S$. aureus (29.52\%), followed by E. coli (17.34\%), Klebsiella (15.13\%), Coagulase negative Staphylococcus (9.96\%), Pseudomonas 


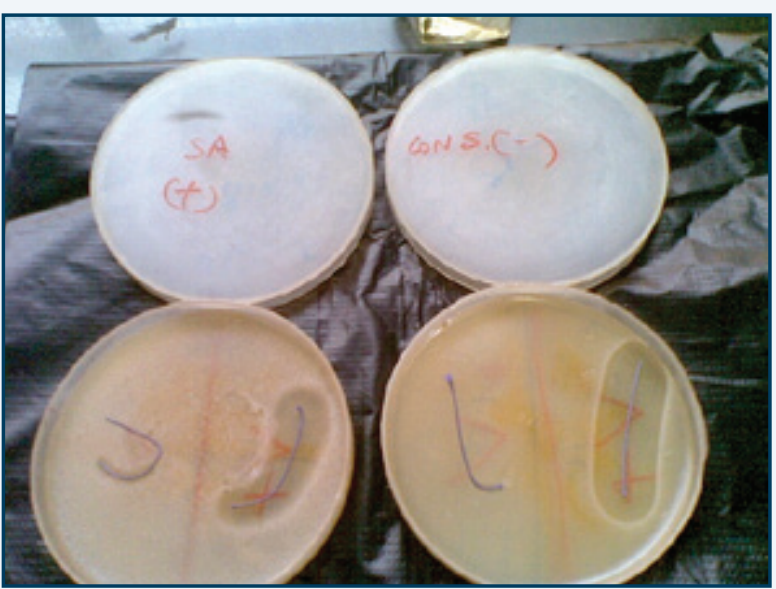

Figure 1. Good zone of inhibition around coated suture, no zone of inhibition around uncoated suture against $S$. aureus and CoNS

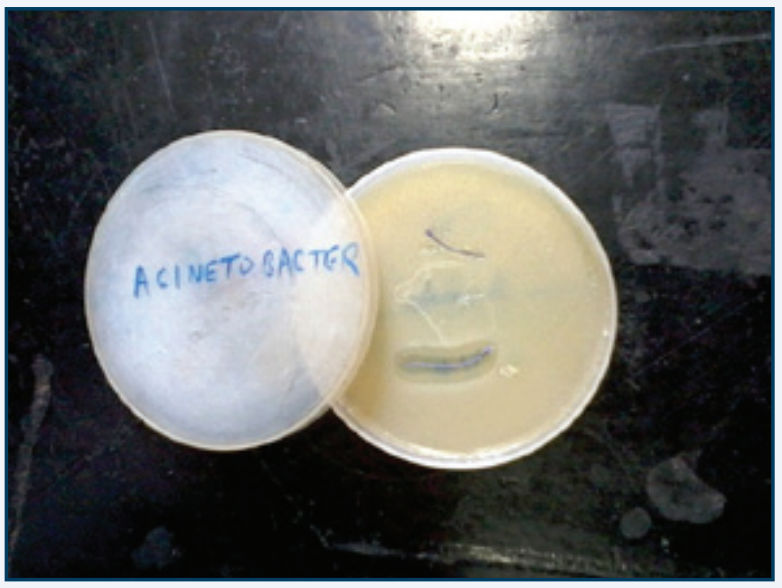

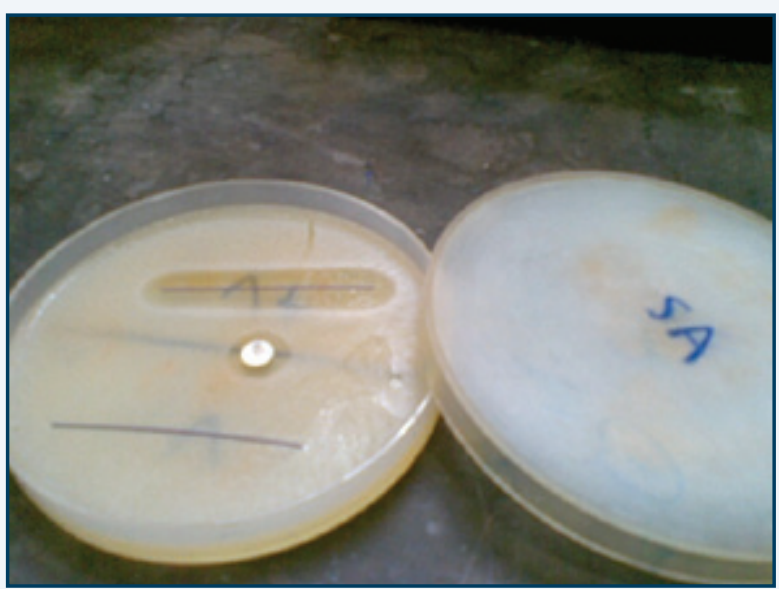

Figure 2. Good zone of inhibition around coated suture, no zone of inhibition around uncoated suture and $<21 \mathrm{~mm}$ zone of inhibition around cefoxitin disc against MRSA.

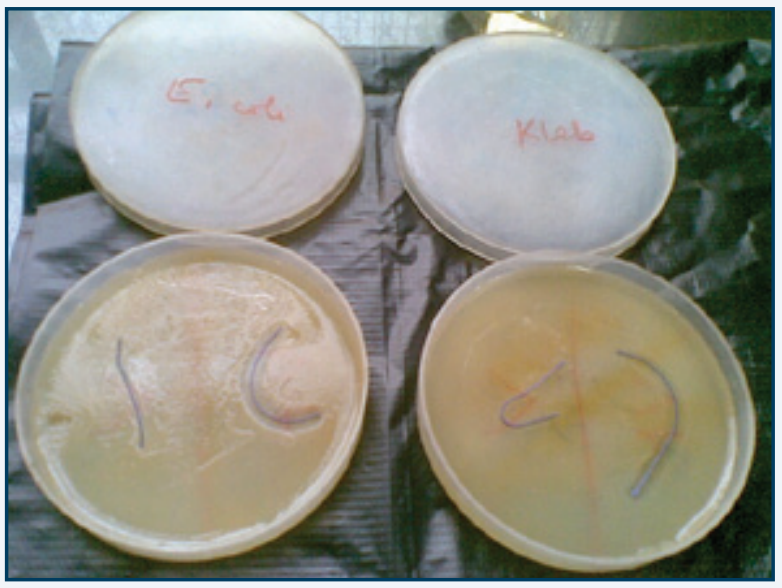

Figure 3. Good zone of inhibition around coated suture, no zone of inhibition around uncoated suture against Acinetobacter, E. coli and Klebsiella spp.
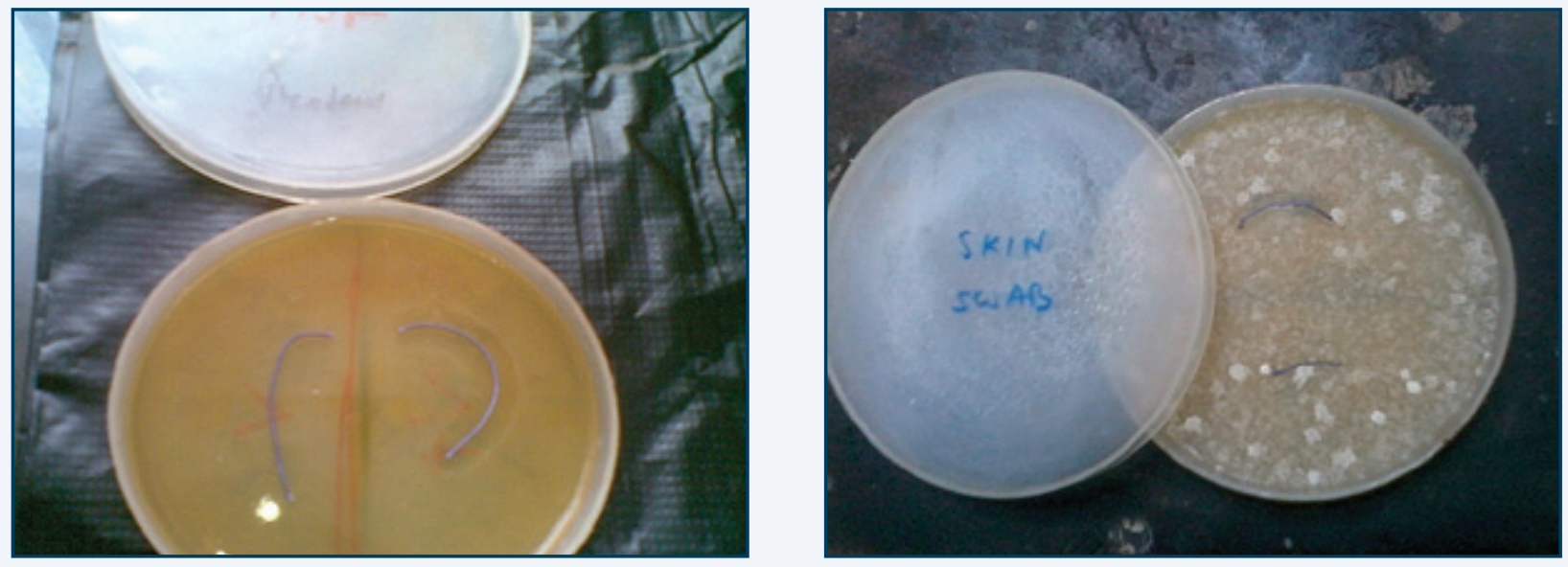

Figure 4. Good zone of inhibition around coated suture, no zone of inhibition around uncoated suture against Proteus and skin commensals 

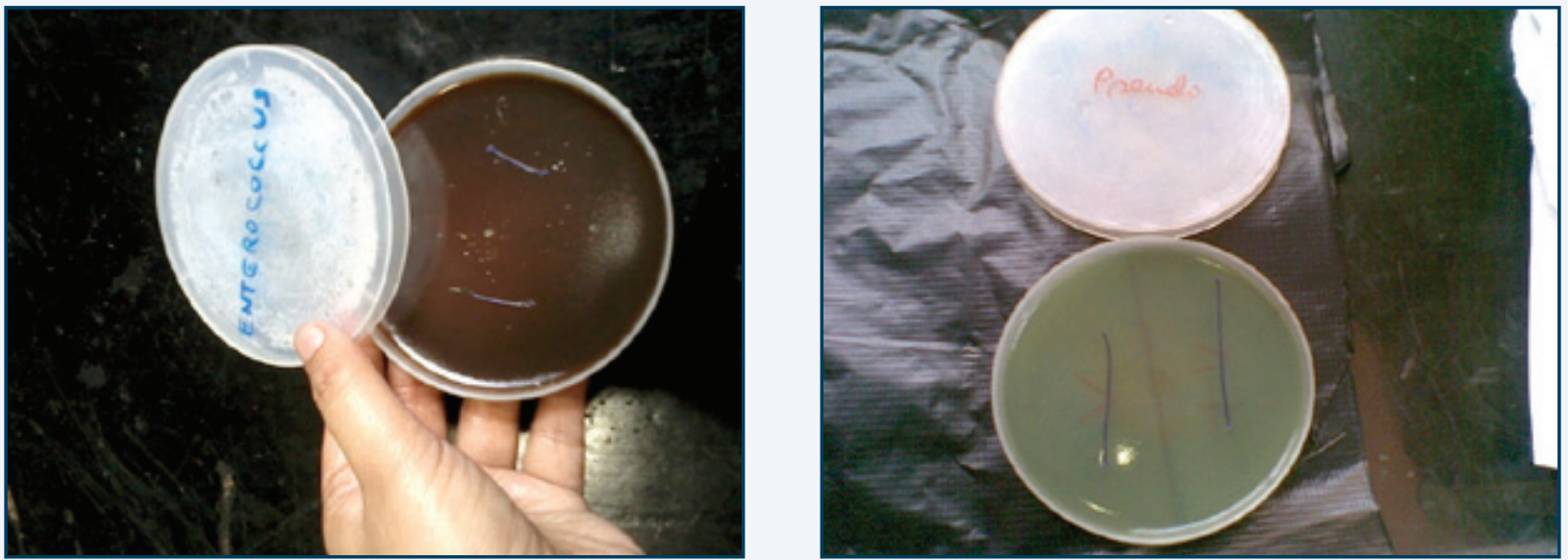

Figure 5. No zone of inhibition around coated and uncoated suture against Enterococcus and Pseudomonas spp.

(9.22\%), Proteus (6.64\%), Enterococcus (5.53\%), Citrobacter (3.69\%), and Acinetobacter spp. (2.95\%).

\section{In-vitro testing of triclosan coated and uncoated suture against the bacteria isolated from SSI}

For each bacteria when the number of isolates was more than 20 (e,g. in S. aureus, E. coli, Klebsiella, Coagulase negative Staphylococcus, Pseudomonas), $50 \%$ of the isolates were randomly selected and tested against triclosan coated and uncoated suture. But when the number of isolates was less than 20 (e.g. in Proteus, Enterococcus, Citrobacter and Acinetobacter spp.), all the isolates were tested against triclosan coated and uncoated suture. The zone of inhibition around triclosan coated suture and around uncoated suture against these common isolates causing SSI was measured perpendicular to the midpoint of the suture material. After overnight incubation, a good zone of inhibition was found around triclosan coated suture but no such zone was found around uncoated suture (Table I, Figures 1 and 3).

\section{Testing of triclosan coated suture against MRSA and MRSE}

Twenty four (30\%) MRSAs were isolated from these wound infections and after performing similar experiment with MRSA, it was observed that plates containing MRSA strains showed a good zone of inhibition around coated suture (Figure 2), no zone of inhibition around uncoated suture and $<21 \mathrm{~mm}$ zone of inhibition around cefoxitin disc. Similar results were found with MRSE strains.

\section{Testing of triclosan coated suture against skin commensals}

A fair zone of inhibition (4-6mm) for triclosan coated sutures and no zone of inhibition for uncoated sutures was seen against skin commensals (Figure 4).

The experiments were repeated three times, with coated and uncoated sutures against each bacteria and the coated suture came up with consistently good results against all the strains of all isolated bacteria from SSI including the skin commensals except Pseudomonas and Enterococcus spp. where there was no zone of inhibition around triclosan coated sutures (Figure 5).

\section{Discussion}

Triclosan-coated polyglactin sutures inhibited in vitro growth of $S$. aureus, including MRSA, and $S$. epidermidis, whose antibacterial effect was robust and did not diminish when sutures were placed in an aqueous environment for up to 7 days. ${ }^{19}$ Cultures of $S$. aureus, MRSA, S. epidermidis (biofilm-positive) and E. coli were inoculated in another study with triclosan-coated and non-coated polyglactin and reductions in bacterial adherence were observed with antibacterial activity persisting for at least $96 \mathrm{~h}^{20}$ The clinical efficacy of triclosan has been studied. Triclosan-coated poliglecaprone suture has been evaluated to inhibit bacterial colonization by $E$. coli and $S$. aureus in the mouse and guinea pig. ${ }^{17}$ In a study of post-appendicectomy SSIs in children, conventional treatment was compared with the use of triclosancoated sutures or gentamicin-impregnated sponges, 


\section{Table I. Zone of inhibition around coated and uncoated sutures}

\begin{tabular}{lrr} 
Organism isolated (\%) & Zone of inhibition (coated suture) & Zone of inhibition (uncoated suture) \\
\hline S. aureus (29.52\%) & $14-18 \mathrm{~mm}$ & $0-2 \mathrm{~mm}$ \\
\hline MRSA & $12-15 \mathrm{~mm}$ & $0-1 \mathrm{~mm}$ \\
\hline CoNS (9.96\%) & $14-20 \mathrm{~mm}$ & $0-2 \mathrm{~mm}$ \\
\hline \multicolumn{1}{c}{ MRSE } & $12-18 \mathrm{~mm}$ & $0-1 \mathrm{~mm}$ \\
\hline Enterobacteriaceae & $6-10 \mathrm{~mm}$ & $0-1 \mathrm{~mm}$ \\
\hline E. coli $(17.34 \%)$ & $6-8 \mathrm{~mm}$ & $0-1 \mathrm{~mm}$ \\
\hline Klebsiella (15.13\%) & $6-8 \mathrm{~mm}$ & $0-1 \mathrm{~mm}$ \\
\hline Citrobacter (3.69\%) & $6-10 \mathrm{~mm}$ & $0-1 \mathrm{~mm}$ \\
\hline \multicolumn{1}{c}{ Proteus $(6.64 \%)$} & $9-11 \mathrm{~mm}$ & $0-1 \mathrm{~mm}$ \\
\hline Acinetobacter $(2.95 \%)$ & $0-1 \mathrm{~mm}$ & $0-1 \mathrm{~mm}$ \\
\hline Enterococcus $(5.53 \%)$ & $0-2 \mathrm{~mm}$ & $0-1 \mathrm{~mm}$
\end{tabular}

inserted prior to wound closure. ${ }^{21}$ The antimicrobial sutures and sponges significantly reduced SSIs. In a clinical prosthetic study, which evaluated the incidence of CSF shunt infections following use of triclosan-coated or conventional sutures, the infection rate was significantly reduced in the triclosan-coated suture group $(4.3 \%$ vs $21 \%){ }^{22}$ Assuming an SSI reduction using triclosan-coated sutures of only $10 \%$, use of such a suture, based on current costs, would avoid 100 SSIs yielding a cost saving of $€ 976,000$. $^{23}$

The skin is a dynamic home of a large number of bacteria, with up to 3 million microorganisms on each square centimeter of skin. ${ }^{24} \mathrm{SSI}$ commonly occurs from commensal organisms such as coagulase negative staphylococci, diphtheroids, Pseudomonas, and Propionibacterium species that are consistently present on patient's skin. The antibcterial effect of triclosan coated suture over skin commensals were seen in this study.

Thus it might be assumed that use of triclosan coated suture could significantly reduce the SSI rate and thereby cost and duration of hospital stay. It was highly effective in-vitro against the common bacteria isolated from post-operative wound infections as well as skin commensals except Pseudomonas and Enterococcus spp. The increased cost of the coated suture material when weighed against the cost of wound infections caused directly by the cost of care as well as indirectly through the loss of economic productivity compared favourably.

\section{References}

1. Mangram AJ, Horan TC, Pearson ML. Guideline for prevention of surgical site infections. Infect Control Hosp Epidemiol 1999; 20: 247e78.

2. Barbolt TA. Chemistry and safety of Triclosan, and its use as an antimicriobal coating on coated Vicryl*Plus antibacterial suture (coated polygalactin 910 suture with Triclosan. Surg Infect (Larchmt) 2002; 3: S45e53 [review].

3. Blomstedt B, Osterberg B, Bergstrand A. Suture material and bacterial transport. An experimental study. Acta Chir Scand 1977; 143: 71-73.

4. Osterberg B, Blomstedt B. Effect of suture materials on bacterial survival in infected wounds. An experimental study. Acta Chir Scand 1979; 45: 431-434.

5. Chu CC, Williams DF. Effects of physical configuration and chemical structure of suture materials on bacterial adhesion. A possible link to wound infection. Am / Surg 1984; 147: 197 204. http://dx.doi.org/10.1016/0002-9610(84)90088-6

6. Howe CW, Marston AT. A study on sources of postoperative staphylococcal infection. Surg Gynecol Obstet 1962; 115: 266-275.

7. Everett WG. Suture materials in general surgery. Prog Surg 1970; 8: 14-37.

8. Edlich RF, Panek PH, Rodeheaver GT, Turnbull VG, Kurtz LD, Edgerton MT. Physical and chemical configuration of sutures in the development of surgical infection. Ann Surg 1973; 177: 679688. http://dx.doi.org/10.1097/00000658-197306000-00006

9. Smolianskaia AZ, Dronova OM, Zhukovskii VA. In vitro activity of surgical suture materials containing cephalosporin antibiotics. Antibiot Khimioter 1994; 39: 45-48.

10. Rodeheaver GT, Kurtz LD, Bellamy WT, Smith SL, Farris H, Edlich RF. Biocidal braided sutures. Arch Surg 1983; 118: 322-327. http://dx.doi.org/10.1001/archsurg.1983.01390030054008

11. Polous IM, Goshchinskii VB, Grivenko SG, Belykh SI, Davydov $A B$, Bikaliuk IF. The validation of the use of iodine-containing suture thread in surgical practice. Klin Khir 1993; 1: 49-51.

12. Slater-Radosti C, Van Aller G, Greenwood R, et al. Biochemical and genetic characterization of the action of triclosan on Staphylococcus aureus. I Antimicrob Chemother 2001; 48: 1-6. http://dx.doi.org/10.1093/jac/48.1.1

13. McMurry LM, Oethinger M, Levy SB. Triclosan targets lipid synthesis. Nature 1998; 394: 531-532. http://dx.doi. org/10.1038/28970 
14. Levy CW, Roujeinikova A, Sedelnikova S, et al. Molecular basis of triclosan activity. Nature 1999; 398: 383. http:// dx.doi.org/10.1038/18803

15. Gomez-Escalada M, Harwood JL, Maillard JY, et al. Triclosan inhibition of fatty acid sysnthesis and its effect on growth of Escherichia coli and Pseudomonas aeruginosa. I Antimicrob Chemother 2005; 55: 879-882. http://dx.doi.org/10.1093/jac/ dki123

16. Ming $X$, Nichols $M$, Rothenburger $S$. In vivo antibacterial efficacy of MONOCRYL plus antibacterial suture (Poliglecaprone 25 with triclosan). Surg Infect (LarChmt) 2007; 8: 209-214. http://dx.doi.org/10.1089/sur.2006.004

17. Storch ML, Rothenburger SJ, Jacinto G. Experimental efficacy study of coated Vicryl plus antibacterial suture in guinea pigs challenged with Staphylococcus aureus. Surg Infect (Larchmt) 2004; 5: 281-288. http://dx.doi.org/10.1089/sur.2004.5.281

18. Ming X, Rothenburger S, Nichols MM. In vivo and in vitro antibacterial efficacy of PDS plus (polydioxanone with triclosan) suture. Surg Infect (Larchmt) 2008; 9: 451-457. http://dx.doi.org/10.1089/sur.2007.061

19. Rothenburger S, Spangler D, Bhende S, Burkley D. In vitro antimicrobial evaluation of Coated Vicryl* Plus Antibacterial Suture (coated polyglactin 910 with triclosan) using zone of inhibition assays. Surg Infect (Larchmt) 2002; 3 (Suppl 1): S79-87. http://dx.doi.org/10.1089/sur.2002.3.s1-79
20. Edmiston CE, Seabrook CR, Goheen MP, et al. Bacterial adherence to surgical sutures: can antibacterial-coated sutures reduce the risk of microbial contamination? I Am Coll Surg 2006; 203: 481-489. http://dx.doi.org/10.1016/j. jamcollsurg.2006.06.026

21. Pico RB, Jiménez LA, Sánchez MC, et al. Prospective study comparing the incidence of wound infection following appendectomy for acute appendicitis in children: conventional treatment versus using reabsorbable antibacterial suture or gentamicin-impregnated collagen fleeces. Cir Pediatr 2008; 21: 199-202.

22. Rozzelle CJ, Leonardo J, Li V. Antimicrobial suture wound closure for cerebrospinal fluid shunt surgery: a prospective, double-blinded, randomized controlled trial. JNeurosurg Pediatr 2008; 2: 111-117. http://dx.doi.org/10.3171/ PED/2008/2/8/111

23. Leaper D, McBain AJ, Kramer A, et al. Healthcare associated infection: novel strategies and antimicrobial implants to prevent surgical site infection. Ann $R$ Coll Surg Engl 2010; 92: 453-458. http://dx.doi.org/10.1308/00358841 0X12699663905276

24. Montague S, Watson R, Herbert R. Physiology for Nursing Practice. 3rd ed. New York: Elsevier; 2005. 